\title{
Un nuevo capítulo de epistemología teológico-pastoral: aportes a la comprensión de los signos de los tiempos
}

\section{A new chapter of theological-pastoral epistemology Contributions to the understanding of the signs of the times}

Carlos Schickendantz

\section{Resumen}

La categoría de "signos de los tiempos" simboliza la introducción de una importante novedad en la historia del magisterio conciliar y de la metodología teológica. El presente artículo ofrece dos desarrollos que desean contribuir a la profundización de la temática. Gaudium et spes aportó una nueva forma de conocimiento, tan nueva que autores relevantes dudaron entonces de su autoridad. Una amplia mayoría del episcopado alemán se alineó entonces en torno a un texto crítico de Karl Rahner inédito hasta fecha reciente. Además de la presentación y comentario de ese informe se ofrece el análisis de una contribución posterior de Rahner que brinda respuestas a sus propias preguntas dirigidas al esquema de la Constitución. En un segundo momento, el artículo considera la temática desde un ángulo diferente, pero complementario. La forma de proceder "no ya deductiva y abstracta sino inductiva y concreta" (Congar) planteó en el posconcilio la pregunta acerca del estatuto teológico de la presencia de la Palabra de Dios en y por la historia. En ese marco se examina aquí el uso de la noción de "lugar teológico" en algunos autores latinoamericanos, especialmente I. Ellacuría, y se propone una profundización ulterior de su comprensión. 
Palabras clave: Gaudium et spes. Karl Rahner. Lugar teológico. Método teológico.

\begin{abstract}
The category "signs of the times" symbolizes the introduction of an important novelty in the history of the conciliar magisterium and of the theological methodology. This article offers two developments that wish to contribute to the deepening of the subject. Gaudium et spes brought a new form of knowledge, so new that relevant authors hesitated at the time of his authority. A large majority of the German episcopate then lined up around a critical text by Karl Rahner unpublished until recently. In addition to the presentation and commentary of this report, it offers the analysis of a later contribution by Rahner that provides answers to his own questions addressed to the outline of the Constitution. In a second moment, the article considers the subject from a different angle, but complementary. The way of proceeding "no longer deductive and abstract but inductive and concrete" (Congar) raised in the post-conciliar period the question about the theological status of the presence of the Word of God in and through history. In this context, the use of the notion of "theological place" is examined in some Latin American authors, especially I. Ellacuría, and a further deepening of it understanding is proposed.
\end{abstract}

Keywords: Gaudium et spes. Karl Rahner. Theological place. Theological method.

\title{
Introducción
}

La categoría de signos de los tiempos constituye, a no dudarlo, uno de los conceptos característicos utilizados en la vida de las iglesias hoy, en general, y en las más variadas corrientes teológicas contemporáneas. Pero su uso generalizado no deja de plantear interrogantes acerca de su significación. G. Routhier, por ejemplo, que reconoce que la expresión signos de los tiempos ha introducido "una gran novedad" en el hecho de que afirma que el Evangelio no puede ser proclamado "desde fuera" sino en diálogo, en particular, con la escucha de las aspiraciones humanas, advierte que se supone a menudo que el "sentido" del concepto utilizado es evidente 
para todos y que la "expresión es perfectamente transparente", como "si no pusiera problemas" para su comprensión. Es una noción a menudo "mal definida" por quienes la emplean, de "contenido fluido e impreciso", utilizada además de una "manera acrítica", anota el teólogo de Quebec. Su trabajo de 2011, precisamente, se orienta a aclarar la significación, particularmente mediante el estudio de su inclusión en el Vaticano II. ${ }^{1}$ Una de las tareas de una publicación atenta al estado de la cuestión en la bibliografía internacional debe llamar la atención sobre este hecho. En artículos anteriores he aducido ejemplos de múltiples autores que, con matices, confirman este diagnóstico que puede sintetizarse en una triple perplejidad: sobre el significado de la misma noción, la criteriología de discernimiento y la articulación entre los llamados principios teológicos y los acontecimientos históricos a los que alude el uso de la categoría. ${ }^{2}$ En este sentido, la constatación hecha por G. Gutiérrez en 1971 parece conservar actualidad: "Pese a su enorme interés, la noción de signos de los tiempos está lejos de encerrar un contenido claro y bien delimitado". ${ }^{3}$

Particularmente en las últimas décadas, debido a múltiples factores, se ha tomado mayor conciencia en buena parte de la bibliografía actual acerca de las controversias que acompañaron el proceso de la formación de Gaudium et spes. Dichos debates tuvieron un punto central, no exclusivo, en la estructura misma de la Constitución que la noción de signos de los tiempos simboliza.

En el marco de la compleja historia de la redacción de la Constitución pastoral en la última versión del llamado Esquema XIII enviada a los padres conciliares en mayo de 1965 se incluía la estructura definitiva del documento que, como afirma $\mathrm{C}$. Theobald, "estaba fundada sobre el método inductivo 'ver-juzgar-obrar' de la Acción Católica, introducido como esquema estructurante en la primavera de 1965". De esta forma, desde ese momento la "interpretación de los signos de los tiempos" fue "adquirida como principio teológico a partir del cual se organiza el conjunto de la

\footnotetext{
${ }^{1}$ ROUTHIER, G. “'Les signes du temps'. Fortune et infortune d'une expression du Concile Vatican II". Transversalités 118 (2011), pp. 101, 79s. respectivamente.

${ }^{2}$ Cf. SCHICKENDANTZ, C. "Un cambio en la ratio fidei. Asociación (aparentemente ilícita) entre principios teológicos y datos empíricos”. Teología y Vida 57 (2016), pp. 158-161.

${ }^{3}$ GUTIÉRREZ, G. Teología de la liberación. Perspectivas. Lima: CEP, 1971, p. 24, nota 29. Cf. MERINO, P. La categoría teológica Signos de los tiempos. Desde el Concilio Vaticano II al Pentecostés de Aparecida y Francisco. Bogotá: USTA, 2014.
} 
futura constitución". ${ }^{4}$ El debate acerca de este principio y su puesta en obra en la versión de 1965 de la futura Gaudium et spes colaboró decididamente al surgimiento de la controversia franco-alemana de esos meses. Como ha afirmado con acierto H.-J Sander, la Constitución aportó una nueva forma de conocimiento en el debate conciliar, tan nueva que autores tan relevantes como por ejemplo K. Rahner dudaron entonces de su autoridad. ${ }^{5}$ Pero es posible detectar preguntas análogas en aquel momento incluso entre autores de lengua francesa. Yves Congar, por ejemplo, constataba en octubre de 1965 la novedad y los interrogantes de fondo sobre este documento al poner de relieve su inédito título: constitutio pastoralis. "Es un título nuevo con el que se ha querido subrayar el género particular de este documento. ¿Cuál es exactamente su estatuto desde el punto de vista de la criteriología teológica?"6

Con la documentación hoy existente el juicio de G. Routhier sobre el rol de "los alemanes", que él adjudica sobre todo a los obispos que se expresaron en el aula conciliar, parece completamente acertado. "No era sencillamente la exactitud de lo que el esquema decía lo que originaba dificultades a los alemanes y a los italianos", afirma, aunque es verdad que había múltiples objeciones a diversos conceptos del documento. En realidad, "ellos cuestionaban el método mismo del esquema. Aunque no se dijo claramente, lo que disgustaba a estos oradores era el método inductivo del esquema, su enfoque empírico y descriptivo. Se sentían desconcertados porque no hallaban un tratado clásico sobre antropología cristiana". ${ }^{7}$ Era el "corazón del conflicto", en palabras de C. Theobald. ${ }^{8}$

El debate aludido no es solo de interés para los investigadores del Vaticano II, puesto que allí se hizo evidente que estaba en juego un asunto

${ }^{4}$ THEOBALD, C. Le concile Vatican II. Quel avenir? Cerf: Paris, 2015, pp. 228-229. Cf. SANDER, H-J. "Theologischer Kommentar zur Pastoralkonstitution über die Kirche in der Welt von heute Gaudium et spes". In: HÜNERMANN, P.; HILBERATH, B.-J. (Eds.). Herders Theologischer Kommentar zum Zweiten Vatikanischen Konzil. Band 4. Freiburg/Basel/Wien: Herder Verlag, 2005, pp. 638ss., 644ss., 715.

${ }^{5}$ SANDER, H.-J. “Theologischer Kommentar zur Pastoralkonstitution”, p. 655.

${ }^{6}$ CONGAR, Y. "Constitución sobre la Iglesia y el mundo (esquema XIII)”. In: CONGAR, Y. Diario del Concilio. Cuarta sesión. Barcelona: Estela, 1966, p. 58.

${ }^{7}$ ROUTHIER, G. "Finalizar la obra comenzada: la experiencia del cuarto período, una experiencia que ponía a prueba". In: ALBERIGO, G. Historia del Concilio Vaticano II. Volumen V. Un Concilio de transición. El cuarto periodo y la conclusión del Concilio. Salamanca: Sígueme, 2008, p. 143.

${ }^{8}$ Cf. THEOBALD, C. Le concile Vatican II, pp. 227, 229, etc. 
mayor: una relativa pero importante novedad en la historia del magisterio conciliar y en el desarrollo del método de la ciencia teológica. La advertencia de Congar en 1968, sin duda una de las personas más cualificadas para realizar esta evaluación, no puede minusvalorarse: "El concilio, con el Esquema XIII, pretendía iniciar una forma relativamente nueva de teología, no ya deductiva y abstracta sino inductiva y concreta. (...) Pienso que el significado epistemológico de este hecho es muy importante". ${ }^{9}$

Por otra parte, el estudio de la novedad metodológica apuntada debe advertir las diferentes formas de recepción que ella tuvo en diversas regiones de la Iglesia católica e, incluso, en personalidades decisivas en la vida eclesial en las décadas posteriores. Desde este punto de vista J. Ratzinger y J. Bergoglio, Benedicto y Francisco representan dos tradiciones recientes diversas; en ellos se visibilizan las diferencias que emergieron en la confección de Gaudium et spes, precisamente en el punto que fue "el corazón del conflicto" (Theobald). Es pertinente interpretar las peculiaridades y disimilitudes entre estos dos pontificados también a partir de esta clave de lectura. ${ }^{10}$

La vinculación que hay entre una determinada metodología para pensar la fe -en este caso una forma de proceder "no ya deductiva y abstracta sino inductiva y concreta" (Congar) - y un estilo de configurar la vida cotidiana de la Iglesia en los más diversos ámbitos ha sido verificada en la fase posconciliar latinoamericana. En este sentido bajo la apariencia de representar un asunto teórico y abstracto esta perspectiva metodológica, central en una teología de los signos de los tiempos y popularizada en América Latina con el método ver-juzgar-actuar, está en la base de varias de las experiencias teológicopastorales más creativas de estas décadas. Como expresa A. Brighenti ella ha impulsado las prácticas eclesiales populares que desembocaron en la opción por los pobres, en el aprecio de la religiosidad popular, en la formación de las comunidades eclesiales de base, en la práctica de la lectura popular de la Biblia, en el desarrollo de la pastoral social, la militancia ciudadana y la propia Teología de la liberación. ${ }^{11}$

\footnotetext{
${ }^{9}$ CONGAR, Y. y otros, La respuesta de los teólogos (C. Lohlé, Buenos Aires 1970) 11-18, 14 (cursiva mía).

${ }^{10}$ Una versión preliminar de este texto fue presentada en el Simposio Internacional: A Ecclesiologia do Papa Francisco (Rio de Janeiro, Brasil, 7-9 de setiembre 2017), organizada por la Sociedade Brasileira de Teologia sistemática (SBTS). Agradezco una vez más en la persona de su presidente, M. de França Miranda, la cordial invitación y el diálogo de esos días.

${ }^{11}$ Cf. BRIGHENTI, A. "Método ver-julgar-agir". In: DECIO PASSOS, J.; LOPES SANCHEZ, W. (Coord.). Dicionário do Concílio Vaticano II. São Paulo: Paulinas, 2015, p. 608.
} 
En este marco histórico y teórico, eclesial y teológico, el presente artículo, en el panorama de la bibliografía ya existente, ofrece dos desarrollos que desean contribuir a la profundización de la temática. Como he recordado más arriba, amplios sectores del episcopado alemán formularon reservas importantes al borrador de 1965 de la futura Constitución pastoral. G. Turbanti afirma que ellos "representaron la amenaza más consistente al buen resultado del esquema durante la última sesión del concilio." 12 Con matices, a veces importantes, una amplia mayoría de dicho episcopado se alineó en torno a un texto crítico de Karl Rahner - de trece páginas en su versión de mayo de 1965- que, en buena parte, ha permanecido inédito hasta fecha reciente. En la información que Y. Congar aporta en su diario del Concilio sobre la importante reunión entre obispos y teólogos belgas, franceses y alemanes del 17 de setiembre de 1965, el teólogo francés escribe lo que puede considerarse, en alguna medida, una síntesis de las observaciones del teólogo alemán desde el punto de vista metodológico: "Rahner insiste sobre el problema de gnoseología: quién habla, a nombre de quién, con qué certeza; ¿de dónde se obtiene lo que se dice?". ${ }^{13}$ Incluyo en este primer momento del artículo, además de la presentación y comentario del informe de 1965 en el aspecto que interesa a esta contribución, el análisis de un texto posterior del mismo autor, de 1967, que, hasta cierto punto, ofrece una respuesta a sus propias preguntas dirigidas al esquema de la Constitución.

En segundo lugar, considero la temática desde un ángulo diferente, pero complementario. La forma de proceder "no ya deductiva y abstracta sino inductiva y concreta" (Congar) planteó la pregunta en el posconcilio, aunque no en estos términos, acerca del estatuto teológico de la presencia de la Palabra de Dios en y por la historia, en sí mismo y, particularmente, en relación al estatuto de la presencia de la Palabra de Dios consignada en las Escrituras. La noción de lugar teológico, con una historia análoga a la de signos de los tiempos por sus significados múltiples e incluso equívocos, ha desempeñado un rol particular en los textos teológicos latinoamericanos de estas décadas. No es posible exponer esa historia aquí, pero deseo mostrar un punto necesitado de ulterior profundización a partir de la consideración de uno de los autores de nuestra región que más y mejor trabaja la temática: el teólogo de Fortaleza, Brasil, Francisco de Aquino. Su competencia sobre las obras de I. Ellacuría y

12 TURBANTI, G. Un Concilio per il mondo moderno. La redazione della costituzione pastorale 'Gaudium et spes' del Vaticano II. Bologna: Il Mulino 2000, p. 620.

${ }^{13}$ CONGAR, Y. Mon Journal du Concile. Paris: Les Éditions du Cerf, 2002, Vol. II, p. 395. 
J. Sobrino, precisamente en la perspectiva metodológica, colabora a sacar a la luz la pregunta por la naturaleza de este lugar teológico, la realidad histórica actual discernida en el Espíritu. O, en otras palabras, la "autoridad teológica de los acontecimientos históricos". ${ }^{14}$ Se trata de una cuestión que persigo hace tiempo y la primera tarea, estimo a partir de mis lecturas, consiste en mostrar de la forma más precisa posible que existe un asunto irresuelto que, además, no es irrelevante.

\section{Dificultades para precisar un "nuevo" modo de conocimiento eclesial - K. Rahner}

El cardenal arzobispo de Múnich, J. Döpfner solicitó a Rahner la preparación de unas observaciones sobre el esquema de la futura Gaudium et spes. El texto confeccionado por el teólogo alemán posee dos partes, la primera dedicada a observaciones de carácter general y la segunda a observaciones singulares, a las que se añade un apéndice escrito por O. von Neil-Breuning con comentarios al capítulo sobre la vida económica. Este documento ha sido publicado recientemente en la edición de las obras completas del teólogo alemán, ${ }^{15}$ aunque era parcialmente conocido por el uso que hizo el cardenal Döpfner en su discurso en el aula conciliar el 22 de setiembre de 1965 en nombre de 91 padres de lengua alemana y escandinava y por su inclusión como material conciliar, a pedido del mismo cardenal, a renglón seguido de su exposición. ${ }^{16}$

La primera parte -Generalia- posee, a su vez, una triple división, secciones desiguales en su extensión. Destaca, primero, los "defectos" del esquema presentado, luego reconoce en forma breve algunos aspectos dignos "de alabar" y, finalmente, propone unas sugerencias acerca de cómo proceder en el debate conciliar que se avecinaba: “Quid ergo faciendum?” Reconoce, en esta última sección, que se ha realizado un extenso trabajo sobre la Constitución y de que existen tantas expectativas sobre ella que no es posible excluir el documento del trabajo conciliar. Con el poco tiempo disponible

\footnotetext{
${ }^{14} \mathrm{Cf}$. SCHICKENDANTZ, C. “Autoridad teológica de los acontecimientos históricos: perplejidades sobre un lugar teológico”. Teología 115 (2014), pp. 157-183.

${ }^{15}$ Cf. RAHNER, K. "Animadversiones de Schemate 'De Ecclesia in mundo huius temporis". In: RAHNER, K. Sämtliche Werke, 32/1. Ergänzungen. Freiburg/Basel/Wien: Herder Verlag, 2016, pp. 289-317.

${ }^{16}$ Cf. Acta Synodalia Sacrosancti Concilii Vaticani II, IV/2, pp. 28-33.
} 
antes del final de la cuarta sesión conciliar, Rahner argumenta que no es realista pensar en "mejoras fundamentales" en el esquema. De allí las dos posibilidades que prevé: que el Concilio, luego de la aprobación sustancial del texto, lo consigne a una comisión posconciliar que, después de revisarlo y perfeccionarlo, lo haga público en nombre del Concilio y con la aprobación del papa. Como segunda alternativa posible Rahner prevé la realización de las mejoras necesarias, pero, en ese caso, solicita que el texto reconozca "con sinceridad" sus "imperfecciones"; la Constitución "quiere ser solo el inicio de un diálogo de la Iglesia con el mundo moderno". Ese reconocimiento, piensa el autor, "no daña la autoridad de la Iglesia". "Bajo estas condiciones" la publicación del documento puede resultar, "sin duda, de gran utilidad para la Iglesia y el mundo". ${ }^{17}$

¿Pero qué es lo que suscitaba tanta preocupación en el esquema? En la primera sección del informe Rahner detalla ocho limitaciones de diversa importancia: 1) una "gnoseología teológica insuficiente"; 2) la teología de la relación entre el orden de la creación y de la redención no suficientemente explicada; 3) la "carencia de una verdadera y profunda teología del pecado"; 4) la ausencia de "una teología de la situación escatológica"; 5) la explicación no "suficientemente adecuada" de la "antropología cristiana" que está como "fundamento de todo el esquema"; 6) "graves defectos" en la "latinidad" del texto; un "estilo" en sus afirmaciones que no es digno de un concilio; 7) "múltiples repeticiones superficiales e innecesarias"; 8) afronta, además, problemas de tal envergadura que, por una parte, encuentran allí solo "una respuesta bastante superficial" y que, por otra, requerirían la opinión de "verdaderos expertos" en las materias implicadas. La quinta observación sobre la antropología cristiana- incluye varias indicaciones sobre temáticas afines: la vocación sobrenatural aparece muy breve y tardíamente en el esquema, lo que se designa con el término Dios es más problemático de lo que ordinariamente se supone, el esquema posee una insuficiente teología de la cruz.

La primera parte del informe -sobre las observaciones generalespresenta solo pocos renglones en los cuales se destacan los aspectos positivos del texto. La "crítica es más fácil que las enmendaciones" o mejoras, admite Rahner. Destaca allí "la "estructura (y con ello la argumentación en general) del esquema"; la "Expositio introductoria es incluida justamente y debe

\footnotetext{
${ }^{17}$ RAHNER, K. “Animadversiones de Schemate 'De Ecclesia in mundo huius temporis", pp.
} 299-300. 
conservarse", los anexos de los borradores previos de la Constitución son asumidos en el texto. ${ }^{18}$ Las tres observaciones, aunque breves y abiertas a diversas interpretaciones, son relevantes en el marco de los debates de entonces, incluso con relación a las diversas opiniones entre los mismos autores alemanes. ${ }^{19}$

Indudablemente que, entre las "carencias", la más relevante para Rahner era la metodológica, la criteriología teológica, precisamente ubicada en el primer lugar de su análisis: la "insuficiente gnoseología teológica" en relación con el "conocimiento de la situación concreta del mundo de hoy por parte de los seres humanos y de la misma Iglesia" y en relación con las "conclusiones" o consecuencias "prácticas y concretas" que de esa situación se deducen. El texto afirma:

La carencia de una gnoseología teológica suficiente en cuanto al conocimiento de la situación concreta del mundo de hoy, que debería ser obtenido por los seres humanos o por la Iglesia misma, y en cuanto a las consecuencias verdaderamente prácticas y concretas que resultan de esta situación. Qué significa la fe para la adquisición de este conocimiento, que no puede ella aportar, cuáles son los medios y las fuentes de este conocimiento, esto no está considerado verdadera y suficientemente.

\section{Y continúa Rahner:}

La parte introductoria, ¿está basada solo en "autores idóneos"? ¿Es esa ciencia o saber meramente profano? ¿De dónde se sabe que la condición de la humanidad en el mundo moderno se expone adecuadamente, al menos en cierta forma? ¿Esta descripción es dirigida también por la fe? ¿Puede la Iglesia conocer esa situación mejor y más profundamente que la ciencia profana? Y, además: ¿De qué modo, con qué razón y con qué

\footnotetext{
${ }^{18}$ Cf. RAHNER, K. “Animadversiones de Schemate 'De Ecclesia in mundo huius temporis”, p. 298.

${ }^{19}$ Una diferencia fundamental entre Rahner y Ratzinger en sus críticas a Gaudium et spes, que tienen importantes puntos comunes, radica en que el primero acuerda con conservar el método inductivo del esquema, mientras que el futuro papa, solicita una revisión que tenga como punto de partida la cristología en orden a la exposición sobre la condición humana, en otras palabras, dar vuelta el esquema. En este sentido, el cuestionamiento de Rahner reclama una profundización en la fundamentación del procedimiento inductivo. Cf. SCHICKENDANTZ, C. “¿Una transformación metodológica inadvertida? La novedad introducida por Gaudium et spes en los escritos de Joseph Ratzinger". Teología y Vida 57 (2016), pp. 26-28.
} 
límites, a partir del conocimiento de esa situación, puede la Iglesia deducir o percibir conclusiones verdaderamente concretas en orden a una forma unívoca de actuar humana en tal situación? ¿Qué diferencia existe en relación a ese conocimiento del modo de obrar concreto en esa situación entre el conocimiento de la Iglesia "oficial" (expuesta por el magisterio) y el conocimiento de los mismos cristianos, que quizás pueden y deben formular normas de acción mucho más concretas que la Iglesia como tal? A menudo las normas de acción en el esquema son presentadas de tal forma como si fueran inmediatamente aplicables en orden a determinar una forma de obrar concreta. De facto son a menudo hasta tal punto generales y vagas ("tomar en consideración a la persona humana", etc.) que todos los problemas concretos quedan sin solucionar. Quizás esto resulta de la naturaleza misma de la cosa. Pero esto debería decirse a continuación explícita y sinceramente. ${ }^{20}$

A partir de esos "defectos gnoseológicos", constata Rahner, se aprecia la incomodidad que el esquema le plantea al lector: "casi agobia" con "piadosos principios morales", en sí mismos verdaderos, que teóricamente no podrían ser negados por ninguna persona razonable y que, no obstante, "no indican ningún camino práctico acerca de su aplicación concreta.” El informe continúa:

En el campo de la vida social el texto propone demasiadas cosas (la igualdad de las mujeres, el derecho de todos a participar en la vida pública, etc.). Por cierto, con razón. Pero mucho de esto, por una parte, no puede ser propuesto siempre y en todo lugar como proveniente de manera inmediata y necesaria de la ley natural (lo que no es dicho explícitamente en el esquema) y, por otra parte, cuando se consideran solo las condiciones objetivas de las cosas y de la vida social, no puede ser deducido, con un método de deducción estricto, a partir de principios últimos de la ley natural, puesto que, en cierto modo, también contienen un elemento de una 'decisión histórica colectiva', que tienen también su propia fuerza de obligación para los individuos como tales. ${ }^{21}$

Rahner advierte, al cerrar este punto, que esta "evolución histórica de la aplicación y concretización de los principios supremos de la ley natural no se

${ }^{20}$ RAHNER, K. "Animadversiones de Schemate 'De Ecclesia in mundo huius temporis", pp. 289-290.

${ }^{21}$ RAHNER, K. "Animadversiones de Schemate 'De Ecclesia in mundo huius temporis", p. 291. 
percibe con claridad ni se explica." En este sentido, argumenta, "se proponen principios de acción" que, si bien "de facto son legítimos hoy", "no parecen fundarse ni en la ley natural ni en la tradición de la Iglesia". ${ }^{22}$

Tiene razón Sander cuando argumenta que Rahner, en este texto, ve la ley natural como un camino para afrontar el problema de la relación entre las normas generales y las directivas concretas de acción, aunque destaca que la influencia de las circunstancias concretas sobre las normas generales impide que la Iglesia se convierta en una instancia autoritativa para todas las situaciones vitales. En este sentido es cierto que el argumento allí expuesto se orienta en la línea de una adaptación de axiomas generales a una situación histórica concreta. Siendo correcta esta lectura de Sander, ${ }^{23}$ debe advertirse otro aspecto que destaca más C. Theobald. A su juicio, el punto esencial está dado por la búsqueda colectiva de lo verdadero en su concreción histórica y el estatuto teológico de la decisión común que implica. El informe citado afirma, precisamente, el "elemento de una decisión histórica colectiva" (historicae decisionis collectivae). Si se atiende a su itinerario bibliográfico, argumenta el teólogo de París, el interés de Rahner se centra crecientemente en torno a una reflexión sobre lo que él llama una ética existencial, sobre los ejercicios ignacianos, en dirección a un discernimiento concreto, individual o colectivo, de lo que es conveniente aquí y ahora; realidad que es siempre única e irrepetible y no simplemente deducible de principios generales, con una obligación específica comprensible solo a partir de la experiencia carismática de una llamada de Dios en la historia. ${ }^{24}$ En este sentido, tiene razón Theobald

${ }^{22}$ Cf. RAHNER, K. "Animadversiones de Schemate 'De Ecclesia in mundo huius temporis", p. 292.

${ }^{23}$ El principal problema en Rahner aquí, según Sander, es el significado que tiene el lugar concreto histórico para la formulación de la fe. A su juicio Rahner no solo opera de forma tradicional, preguntándose lo que aporta la fe para el conocimiento de la situación y no en la dirección inversa: lo que la situación del mundo significa para la fe. De este modo, para Sander no habría comprendido cabalmente el nuevo significado de lo pastoral. Cf. SANDER, H.-J. "Theologischer Kommentar", p. 651.

${ }^{24}$ Rahner entiende por "ética existencial" la doctrina según la cual, existe un conocimiento de cada uno, irreductible a los principios generales, respecto a una llamada de Dios, que no sólo ofrece lo posible o permitido, lo tolerado, sino que llama a una tarea determinada y obliga a ella, aunque lo contrario fuese compatible con los principios generales materiales de una ética existencial. Es una reflexión ética que corresponde a la naturaleza única del ser humano como persona espiritual. Cf. RAHNER, K. "Über die Frage einer formalen Existentialethik". In: RAHNER, K. Sämtliche Werke. Kirche in den Herausforderung der Zeit. Bd. 10. Freiburg/Basel/Wien: Herder Verlag, 2003, pp. 302-316; RAHNER, K. "Die Logik der existentiellen Erkenntnis bei Ignatius von Loyola”. In: RAHNER, K. Sämtliche Werke. Bd. 10. Kirche in den Herausforderung der Zeit. 
cuando advierte que la crítica expresada en el informe de 1965 adopta en un texto rahneriano de 1967 -“Sobre la problemática de una 'Constitución pastoral"' - una tonalidad más positiva, buscando desentrañar, precisamente, la naturaleza específica de esta forma de conocimiento. ${ }^{25}$ Aunque, como punto de partida, Rahner reconoce también allí que, a partir del lenguaje tradicional de la Iglesia y su magisterio, "no es fácil decir qué es propiamente una Constitución pastoral". ${ }^{26}$

Rahner argumenta en este artículo a partir de lo que llama "una ontología de lo individual", con "una tesis fundamental ontológica-existencial": una persona singular, y con ella una libre decisión concreta, no es nunca un mero caso particular de una realidad o esencia general y, por tanto, una directiva de acción no puede ser simplemente deducida de forma adecuada solo a partir de principios generales. El obrar concreto es siempre, también, la realización de lo general, está de alguna manera bajo principios generales, de allí que una ética de situación es falsa, pero una decisión libre es siempre más que un mero caso de lo general. ${ }^{27}$

El asunto, en sí mismo, no le presenta problema a Rahner. Por el contrario, el carácter único e indeducible de una situación histórica singular en la que debe tomarse una decisión es una temática bien reflexionada por él. El problema es que esa forma de proceder aparece en este caso en el lenguaje del magisterio conciliar, por lo que surge la pregunta por su exacto estatuto. Rahner afirma que la Constitución, "sin una reflexión teórica", "solo por la vía de los hechos", hizo un análisis del presente, como el que se materializa en la exposición introductoria, "porque necesitaba tal análisis absolutamente". ${ }^{28}$ Pero este punto reclama: hay que conceder que falta una reflexión fundamental acerca de la naturaleza de una constitución pastoral y acerca de este tipo de magisterio. Es la cuestión acerca de la naturaleza de ese conocimiento que, por una parte, la Iglesia necesita para llevar adelante su misión y que, por otra, no se deduce directa y exclusivamente de las fuentes de la revelación.

En el texto de 1967 es interesante la crítica que Rahner aduce allí como proveniente de "teólogos conservadores" en el Concilio: se expresaban

Bd. 10. Freiburg/Basel/Wien: Herder Verlag, 2003, pp. 368-420.

${ }^{25}$ Cf. THEOBALD, C. Le concile Vatican II?, p. 230.

${ }^{26}$ RAHNER, K. "Zur theologischen Problematik einer 'Pastoralkonstitution"”. In: RAHNER, K. Schriften zur Theologie. Vol 8. Freiburg/Basel/Wien: Herder Verlag, 1967, p. 613.

${ }^{27}$ Cf. RAHNER, K. "Zur theologischen Problematik einer 'Pastoralkonstitution"”, p. 617.

${ }^{28}$ Cf. RAHNER, K. “Zur theologischen Problematik einer 'Pastoralkonstitution””, p. 630. 
enérgicamente en contra del análisis del presente, tal como se contenía en la expositio introductiva. "Decían: ¿De dónde sabe la Iglesia lo que debe decirse", cuando ese saber no lo ha podido extraer de las fuentes de conocimiento que ella posee? “Cómo puede ella decir algo vinculante sobre eso?” O, por otra parte, se corre el riesgo de afirmar simples obviedades o bien formular consideraciones que necesitarían más bien una reflexión especializada. Hace falta una "teoría del conocimiento eclesial", si es que es posible expresarse así, afirma Rahner. ${ }^{29}$

De allí la cuestión: "de dónde sabe la Iglesia" cómo debe ser su instrucción concreta, o aproximándonos a su respuesta, “de dónde conoce esa llamada individual de Dios" que le otorga un carácter vinculante a una decisión concreta. La situación de la Iglesia y sus legítimos representantes es aquí análoga a la de un sujeto individual que en una situación particular debe tomar una decisión, entre varias posibles, según su leal saber y entender. El núcleo de la respuesta reside en la idea de una decisión carismática, en la asistencia del Espíritu que conduce a la Iglesia en situaciones siempre nuevas. Si la Iglesia debe anunciar el Evangelio en condiciones inéditas y cambiantes no puede solo repetir las verdades permanentes. Conforme a su propia esencia ella debe obrar históricamente, de allí que "la necesidad y la posibilidad de un conocimiento de la situación, en la que ella actúa y debe realizarse, pertenece también a su esencia, a su realización". ${ }^{30}$ En este sentido, "la Iglesia no puede vivir solo a partir de la revelación de Dios, su desarrollo y correcta interpretación". Para ser ella misma, para poder obrar conforme a su esencia necesita "un conocimiento de la situación en la que vive"; conocimiento que tiene un "carácter carismático" y que no es el fruto, simplemente, de un análisis profano del tiempo. Es la historicidad de la existencia humana -y eclesial- la que muestra los límites de la revelación. Creo que en buena medida tiene razón Theobald cuando afirma que la conciencia de la tesis clásica de la clausura de la revelación conduce a Rahner en este contexto a valorar el fundamento pneumatológico de la historia post Christum y la estructura carismática de la Iglesia. ${ }^{31}$

Con los presupuestos recién explicitados, Rahner formula una especie de tesis que incluso escribe en letra cursiva: la "esencia de una constitución pastoral" consiste en instrucciones o consejos (Weisungen) de la Iglesia

${ }^{29}$ Cf. RAHNER, K. “Zur theologischen Problematik einer 'Pastoralkonstitution'”, pp. 629-630.

${ }^{30}$ Cf. RAHNER, K. “Zur theologischen Problematik einer 'Pastoralkonstitution”, p. 627.

${ }^{31}$ THEOBALD, C. Le concile Vatican II?, p. 232. 
dirigidas, ante todo, para sus propios miembros y, en cierto sentido, para todas las personas que están dispuestas a escuchar a la Iglesia, en instrucciones o "disposiciones que se dan en la situación actual interpretada carismáticamente, como decisiones de la Iglesia, de acuerdo a la llamada carismática de Dios". ${ }^{32}$

El carácter moralmente vinculante, obligante, que Rahner reconoce a una "decisión histórica colectiva" también en el texto de 1965, proviene de su fuente teológica: la "asistencia del Espíritu", la "llamada concreta de Dios para una determinada decisión"; no procede de la mera reflexión y deducción de una norma general, tampoco clara y concretamente a partir de la comprensión general de la fe. "Esa llamada está siempre mediada por la situación concreta en la que se debe tomar una decisión moral". ${ }^{33}$ Es claro para Rahner, igualmente, que, si para el conocimiento de la situación presente y el discernimiento de dicha llamada es imprescindible la asistencia del Espíritu, eso no excluye, sino que más bien exige que la inteligencia del presente, tan multidimensional y complejo, se concrete con la ayuda de las más diversas disciplinas y métodos científicos. ${ }^{34}$

Si en la Constitución pastoral queda abierta la forma cómo se comprende este tipo de documento y de magisterio, de suerte que ella podría ser interpretada como "una colección de principios teológico-morales y socio-políticos singulares" o también, en ciertos puntos, como disposiciones o instrucciones formulados "a partir de una llamada carismática de Dios dirigida a la Iglesia", Rahner opina que el texto continúa la inspiración y conducta de las grandes encíclicas de Juan XXIII, aun cuando en ellas falta también una reflexión sobre esta forma de proceder. Se observa en ellas un tipo de lenguaje que ya no es "doctrinalismo", escribe, es decir, afirmaciones que no pueden "comprobarse como conclusiones obligatorias de principios cristianos generales". ${ }^{35} \mathrm{Al}$ proceder de esta manera, especula Rahner, el papa operó, quizás, con una forma de proceder análoga a la naturaleza de la convocatoria al Vaticano II: esta decisión concreta no puede deducirse, directa y necesariamente, a partir de la consideración de la naturaleza de un concilio, ni tampoco simplemente a partir de la realidad del presente y de la Iglesia.

\footnotetext{
${ }^{32}$ RAHNER, K. "Zur theologischen Problematik einer 'Pastoralkonstitution'”, p. 631.

${ }^{33}$ RAHNER, K. "Zur theologischen Problematik einer 'Pastoralkonstitution"”, p. 620. La categoría de signos de los tiempos, por lo demás, no es tematizada por Rahner en estos textos y contextos.

${ }^{34}$ Cf. RAHNER, K. “Zur theologischen Problematik einer 'Pastoralkonstitution””, pp. 629-630.

${ }^{35}$ Cf. RAHNER, K. "Zur theologischen Problematik einer 'Pastoralkonstitution'”, p. 634-635.
} 
La lectura conjunta de los textos rahnerianos de 1965 y 1967 permiten sacar a la luz con mayor exactitud la verdadera naturaleza de las perplejidades del teólogo alemán frente al esquema de Gaudium et spes de la última sesión conciliar y, al mismo tiempo, encaminar una respuesta a la manifiesta novedad que representaba este nuevo modo de conocimiento, en esta forma y con esta envergadura, no ensayada nunca antes por la Iglesia en su magisterio conciliar. Están esbozados trazos fundamentales de una "teoría del conocimiento eclesial" para una "decisión histórica colectiva" que implica una interpretación teológica del presente. La perspectiva pneumatológica, carismática, tan demandada en la bibliografía posterior, incluso debido a su repetida ausencia, está aquí explícitamente incorporada. Una preocupación importante en Rahner que también le invitaba a ser cauto con este "nuevo" lenguaje magisterial, no formulada por él en este contexto, no debe ser pasada por alto: el temor de una ampliación indebida del campo de enseñanza del magisterio que perjudicara los espacios de libertad, discernimiento y autonomía propios de los creyentes.

Por otra parte, debe reconocerse que un punto importante de las observaciones gnoseológicas de Rahner, presentada también por Döpfner en el aula conciliar, fue explícitamente recogido en la Constitución en las semanas finales del Concilio: fue aceptada la enmienda que destaca la relativa novedad de la materia tratada por la Constitución, el carácter general de sus afirmaciones y la relativa imperfección que acompaña este tipo de texto (GS $90,2){ }^{36}$

Que a la teología, particularmente alemana según Sander, ${ }^{37}$ le ha costado avanzar en la clarificación acerca de la novedad metodológica que expresa la Constitución pastoral y apropiarse de ella puede comprobarse con varios indicadores importantes. Si se revisan textos de W. Kasper, por ejemplo, escritos a mediados de la década de 1980 y, después, en 2011 se advierte que no hay propiamente un progreso en el análisis. ${ }^{38}$ En este punto, América Latina

${ }^{36}$ Cf. MOELLER, C. "Pastorale Konstitution über die Kirche in der Welt von heute. Einleitung”. In: Lexikon für Theologie und Kirche. Das Zweite Vatikanische Konzil III. Freiburg/ Basel/Wien: Herder Verlag, $1968^{2}$, p. 275.

${ }^{37}$ Cf. SANDER, H-J. "Theologischer Kommentar”, pp. 844-853. A su juicio, la interpretación germana permanece adherida a la cuestión del sujeto y su identidad moderna y se muestra incapaz de tomar en serio el elipse formado por el discurso cristiano, por un lado, y por la pluralidad de lugares pastorales, por otro. Falta una aproximación topológica. C. Theobald tiende a suavizar estas fronteras en el análisis de la recepción francesa y alemana. Cf. THEOBALD, C. Le concile Vatican II?, pp. 237-247.

${ }^{38}$ Cf. KASPER, W. "El desafío permanente del Vaticano II. Hermenéutica de las asevera- 
siguió otro camino, menos por su estudio sistemático del proceso conciliar y su clarificación conceptual, más por la puesta en acto de la metodología simbolizada en la categoría de signos de los tiempos, sea en la vida eclesial, sea en su desarrollo teológico.

\section{Diversos sentidos del concepto de lugar teológico - Una cuestión abierta}

F. de Aquino posee varios y muy interesantes trabajos sobre metodología teológica latinoamericana que tienen su mejor expresión, quizás, en la publicación realizada como resultado de su tesis doctoral sobre la obra de Ignacio Ellacuría. Su "formulación del método de la teología de la liberación" la considera de Aquino como "la más densa y consecuente", aunque el autor español-salvadoreño carezca de una presentación sistemática al respecto. ${ }^{39}$ No interesa aquí verificar si la comprensión que de Aquino tiene de Cano, Ellacuría y Sobrino en los textos siguientes que se aducen se ajusta completamente al pensamiento de sus autores. ${ }^{40}$ Para el propósito de esta contribución importa sacar a la luz la comprensión que se tiene del asunto puesto que, probablemente, refleja bien el estado de la cuestión en este ámbito.

De Aquino distingue correctamente "dos comprensiones bien distintas del concepto de 'lugar teológico' cuyos principales representantes son el dominico español Melchor Cano (1509-1560), por un lado, y los jesuitas españoles/salvadoreños Jon Sobrino (1938-) e Ignacio Ellacuría (1930-1989), por otro". ${ }^{41}$ Para Cano lugar teológico designa los "domicilios" o las "fuentes" de argumentos de la teología, es decir, los lugares a partir de los cuales es posible extraer los más diversos argumentos teológicos. Por el contrario, Sobrino y Ellacuría comprenden el lugar teológico "fundamentalmente, como

ciones conciliares”. In: KASPER, W. Teología e Iglesia. Barcelona: Herder, 1989, pp. 410-413; KASPER, W. Katholische Kirche. Wesen - Wirklichkeit - Sendung. Freiburg/Basel/Wien: Herder Verlag, 2011, pp. 454, 567 nota 133.

${ }^{39}$ DE AQUINO, F. Theologie als Einsicht in die Gottesherrschaft. Die Methode der Befreiungstheologie nach Ignacio Ellacuría. Regensburg: Verlag Friedrich Pustet, 2014, pp. 16-17. Es la traducción alemana de la edición portuguesa de 2011.

${ }^{40}$ De Aquino afirma que el concepto y el método de teología de la liberación de Sobrino "es prácticamente el mismo que el de Ignacio Ellacuría, aunque el de Sobrino no posee la misma agudeza”. Cf. DE AQUINO, F. Theologie als Einsicht, p. 19.

${ }^{41}$ DE AQUINO, F. "Sobre o conceito 'lugar teológico"”. Revista Eclesiástica Brasileira 278 (2010), p. 451. 
lugar social", esto es, "el mundo de los pobres y de los oprimidos como lugar privilegiado de revelación y, consecuentemente, de fe (praxis teologal) y de su intelección (teoría teológica)." ${ }^{42}$ Es claro que, en una "sociedad dividida" entre ricos y pobres, una "pobreza dialéctica" formula Ellacuría, el lugar social desempeña "un papel decisivo".

En ese contexto, Ellacuría distingue metodológicamente entre "lugar" y "fuente". Por fuente de la teología comprende el depósito de la fe, esto es, "aquello que de una u otra forma mantiene los contenidos de la fe". Por lugar de la teología entiende "el desde donde se hace la vivencia y la reflexión teológicas", el a partir de dónde (social) se tiene acceso a las fuentes de la fe y de la teología y a partir de dónde esas mismas fuentes dan más o menos de sí. De allí que afirme Ellacuría que no basta acceder a las fuentes para realizar una adecuada reflexión teológica: "gracias al lugar y en virtud de él se actualizan y se hacen realmente presentes unos determinados contenidos." ${ }^{43}$

De Aquino constata también que la distinción entre lugar y fuentes desempeña un "papel fundamental" en la cristología de Sobrino. El lugar de la cristología es muy importante para el uso adecuado tanto de las "fuentes del pasado", los textos, como de las "fuentes del presente", esto es, "la presencia de Cristo en la historia - la fe real en Jesucristo". Aludiendo a Cano, Sobrino afirma que, para algunas cristologías, "el lugar teológico son sustancialmente textos"; para la cristología latinoamericana, por el contrario, "el lugar teológico es, antes que todo, algo real, una determinada realidad histórica en la cual se cree que Dios y Cristo continúan haciéndose presente, por eso es lugar teologal antes que lugar teológico y lugar a partir del cual se pueden

\footnotetext{
${ }^{42}$ DE AQUINO, F. "Sobre o conceito 'lugar teológico", 451. Cf. DE AQUINO, F. Theologie als Einsicht, pp. 280-285. Cf. ELLACURÍA, I. "Los pobres, lugar teológico en América Latina”. In: ELLACURÍA, I. Escrito teológicos I. San Salvador: UCA Editores, 2000, pp. 149-151: "Lugar teológico se entiende aquí, en primer lugar, el lugar donde el Dios de Jesús se manifiesta de modo especial, porque el Padre así lo ha querido. Se manifiesta no sólo a modo de iluminación revelante, sino también a modo de llamada a la conversión. (...) Lugar teológico se entiende aquí, en segundo lugar, el lugar más apto para la vivencia de la fe en Jesús y para la correspondiente praxis de seguimiento. (...) Lugar teológico se entiende aquí, finalmente, el lugar más propio de hacer la reflexión sobre la fe, de hacer teología cristiana."

${ }^{43}$ ELLACURÍA, I. "Los pobres, lugar teológico en América Latina”, p. 152: "Pero para evitar equívocos es conveniente distinguir, al menos metodológicamente, «lugar»y «fuente», tomando como «lugar» el desde donde se hace la vivencia y la reflexión teológicas, y tomando como «fuente» o depósito aquello que de una u otra forma mantiene los contenidos de la fe. La distinción no es estricta, ni menos excluyente, porque de algún modo el lugar es fuente, en cuanto aquél hace que ésta dé de sí esto o lo otro, de modo que gracias al lugar y en virtud de él se actualizan y se hacen realmente presentes unos determinados contenidos".
} 
releer más adecuadamente los textos del pasado". ${ }^{44}$ De hecho, Ellacuría habla de "América Latina como lugar teológico". ${ }^{45}$

De allí, entonces, que de Aquino afirme que hay aquí "dos concepciones bien distintas, no necesariamente contrarias, de 'lugar teológico': 'fuentes' o 'domicilios' de argumentos teológicos (Melchor Cano) y mundo de los pobres y oprimidos como 'lugar social' (Ignacio Ellacuría - Jon Sobrino)." Para la teología son esenciales las fuentes, reconoce, pero también es verdad que el acceso a las fuentes, "que no se reducen a textos, menos aún a textos del pasado", se da siempre en un lugar social más o menos adecuado.

Por todo esto, de Aquino piensa que, de cara a la crítica de la Notificación de la Congregación de la fe de 2006, Sobrino no está sustituyendo la fe apostólica por los pobres de este mundo, considerados como lugar teológico, como lugar de la cristología. Lo que la Congregación llama lugar teológico, siguiendo a Tomás de Aquino y a Cano, Ellacuría y Sobrino lo llaman fuentes de la teología (como lo hace a veces la Congregación y Cano), "reservando la expresión 'lugar teológico' para designar el desde donde, el horizonte, el punto de vista o la perspectiva social en que el teólogo se sitúa y lee e interpreta las propias 'fuentes' de la teología". ${ }^{46}$

Como bien pone de relieve de Aquino, es necesario advertir que la noción de lugar teológico, además de la diferencia de comprensión con M. Cano propia de la conciencia histórica moderna, posee diversos sentidos en Ellacuría: primero, como lugar donde Dios se manifiesta de manera especial (espacio de revelación), en segundo lugar, como el lugar más apto para la vivencia de la fe en Jesús y para la correspondiente praxis de seguimiento (praxis teologal) $\mathrm{y}$, en tercero, como el lugar más propio de hacer la reflexión sobre la fe (hacer teología cristiana). Además, se añade una distinción metodológica que "no es estricta, ni menos excluyente", entre lugar-desde donde se hace la vivencia y reflexión- y fuente -depósito de la fe, contenidos de la fe- en la medida que el lugar hace que la fuente "dé de si esto o lo otro". En este sentido Ellacuría afirma que "de algún modo el lugar es fuente". Por lo tanto, resulta claro

\footnotetext{
${ }^{44}$ DE AQUINO, F. "Sobre o método da teología da libertaçāo. Nos 20 anos do martírio de Ignacio Ellacuría”. Perspectiva teológica 41 (2009), p. 453. Hay que advertir que aquí se añade otro término: lugar teologal. Cf. DE AQUINO, F. Theologie als Einsicht, p. 289.

${ }^{45}$ ELLACURÍA, I. "Los pobres, lugar teológico en América Latina”, p. 142.

${ }^{46}$ DE AQUINO, F. "Sobre o conceito "lugar teológico"”, p. 453. Cf. los distintos aspectos del carácter, dimensión y/o lugar social de la teología: DE AQUINO, F. "El carácter social de la teología”. Revista Latinoamericana de Teología 90 (2013), pp. 279-298.
} 
que el lugar teológico es pensado como lugar social, como "una determinada situación histórica", un desde donde en tanto horizonte de comprensión.

Una pregunta que puede hacerse a este planteo es si el lugar teológico comprendido como lo hacen Ellacuría y Sobrino- es solo lugar hermenéutico o, más bien, debe especificarse con mayor precisión el momento revelatorio, que en algunos pasajes se le adjudica. Si como afirma Ellacuría el mundo de los pobres y oprimidos es "lugar privilegiado de la presencia revelante y de la acción transformante de Dios", 47 "a modo de iluminación revelante", 48 "donde se hace historia la Palabra", ¿por qué no se reconoce que es, o puede serlo conforme al discernimiento que se haga, verdadera "fuente", esto es, un lugar que no es solo horizonte o perspectiva social que permite una determinada comprensión de la fe o que el depósito de la fe dé más de sí? Un lugar de "revelación" -si así es discernido-no puede ser solo "punto de vista, horizonte o perspectiva social" para leer e interpretar las fuentes ya dadas, los "textos del pasado".

Igualmente, si se escribe que "el lugar teológico es, antes que todo, algo real, una determinada realidad histórica en la cual se cree que Dios y Cristo continúan haciéndose presente", surge la pregunta acerca de la naturaleza teológica exacta de esa "presencia". Si se reconoce que, en el hoy, en este caso en el mundo de los pobres, hay "revelación", "manifestación de Dios", debe especificarse la relación, semejanza y diferencia, que existe en el estatuto teológico entre este testimonio de revelación-la realidad histórica-y el llamado depósito de la fe. En otras palabras, si se afirma el carácter de "revelación" no puede decirse simplemente que, gracias a ese lugar social, las fuentes dan más de sí. Es verdad que el depósito de la fe, las fuentes -Escritura, tradición, magisterio, etc.- resultan enriquecidas con la interpretación a partir de un nuevo lugar hermenéutico, "dan más de sí”, o que "de algún modo el lugar es

${ }^{47}$ ELLACURÍA, I. "Los pobres, lugar teológico en América Latina”, p. 157: "En muchos países de América Latina, y especialmente en El Salvador, Guatemala y Nicaragua, los pobres están siendo lugar privilegiado de la presencia revelante y de la acción transformante de Dios...".

${ }^{48}$ ELLACURÍA, I. "Los pobres, lugar teológico en América Latina", p. 149: "Lugar teológico se entiende aquí, en primer lugar, el lugar donde el Dios de Jesús se manifiesta de modo especial, porque el Padre así lo ha querido. Se manifiesta no sólo a modo de iluminación revelante, sino también a modo de llamada a la conversión."

${ }^{49}$ ELLACURÍA, I. "Los pobres, lugar teológico en América Latina”, p. 153: "Los pobres se convierten así en lugar donde se hace historia la Palabra y donde el Espíritu la recrea. Y en esa historización y recreación es donde «connaturalmente» se da la praxis cristiana correcta, de la cual la teología es, en cierto sentido, su momento ideológico" 
fuente", pero un paso ulterior no se realiza con claridad: el esclarecimiento de la naturaleza y la autoridad teológica de ese lugar social "donde se hace historia la Palabra", ese "desde donde" hermenéutico al que se caracteriza, en algunos textos, nada menos que como "revelación". ${ }^{50}$

En este sentido, se aplicaría a esta posición descrita por F. de Aquino la advertencia de Claude Geffré a la meritoria obra de M.-D. Chenu; anota que él habla "explícitamente de revelación continuada", pero que no ha avanzado mucho "en el análisis de la diferencia de estatuto entre la Palabra de Dios consignada en las Escrituras y la Palabra de Dios en y por la historia". ${ }^{1}$

No es relevante aquí si se usa la expresión lugar teológico de manera distinta a la de Cano. Esto es secundario y, por lo demás, legítimo. La cuestión que se plantea es acerca de la naturaleza teológica más exacta del lugar teológico entendido como lugar social, es decir, del "horizonte, el punto de vista o la perspectiva social"; en palabras de Geffré, el estatuto de "la Palabra de Dios en y por la historia", diverso pero análogo al de "la Palabra de Dios consignada en las Escrituras". Y ese estatuto solo puede ser especificado adecuadamente si se atiende a toda la red epistemológica -Escritura, tradición, magisterio, particularmente la enseñanza de los concilios y de la iglesia de Roma, sensus fidelium, consenso en la teología patrística y en la actual, experiencia litúrgica, testimonios de los santos y santas, etc.-, a las diversas vías de transmisión de la Palabra, los diversos lugares teológicos en la terminología de Cano.

En la posición de Ellacuría, tal como ha sido presentada, no obstante la importancia que se le otorga al lugar social, la teología sigue siendo excesivamente una tarea deductiva al no dar cuenta de manera suficiente, desde el punto de vista metodológico, del estatuto y de la autoridad teológica de la emergencia de la Palabra en los acontecimientos históricos de nuestro tiempo. ${ }^{52}$ Se trata de una posible fuente, verdaderamente fuente de la fe en la

\footnotetext{
${ }^{50}$ De hecho, la pregunta por la naturaleza de este lugar y su autoridad teológica se plantea una y otra vez, con diversos términos, cuando se formula su relación con las "fuentes". Por lo demás, hay que advertir que el uso indiscriminado que se advierte en algunos autores acerca de la idea de la realidad histórica como revelación, sin poner de relieve el carácter, por lo menos, análogo que reviste allí el carácter revelatorio en relación con las llamadas diversas fuentes de la teología tampoco colabora al esclarecimiento conceptual que se necesita.

${ }^{51}$ Cf. GEFFRÉ, C. "Théologie de l'incarnation et théologie des signes des temps chez le pére Chenu". In: Marie-Dominique Chenu. Moyen-Âge et modernité. Paris: Centre d'études du Saulchoir, Cerf, 1997, pp. 144-145.

${ }^{52}$ Las precisas formulaciones que se hacen en este punto no son suficientes. Cf. DE AQUINO, F. Theologie als Einsicht, pp. 280-311.
} 
medida en que se reconoce en dichos acontecimientos -en este caso, el mundo de los pobres- una instancia de testimonio de la misma Palabra de Dios. El lugar social adquiere así una autoridad más elevada.

De este modo el servicio de la teología en función de la transformación de la realidad histórica, "como un momento del proceso de realización de la salvación" queda aún más fundamentado y la intelección como "aprehensión de la realidad" e "intelección del reinado de Dios" socialmente mediada radicalmente más exigida..$^{53}$ Desde este punto de vista, aparece más claro todavía que la utilización de las ciencias sociales, en tanto ayudas para comprender la realidad en la que se vive, no puede ser tratadas como momento pre-teológico, sino como mediación constitutiva y fundamental, aunque insuficiente del quehacer teológico como tal. ${ }^{54}$ En síntesis, lo que se demanda es una mayor clarificación metodológica no ofrecida -tampoco- por estos autores. ${ }^{55}$ Un paso metodológico que dé cuenta, mejor de lo que se ha hecho hasta ahora, de la gran novedad de estas décadas en palabras de Gutiérrez: la irrupción de los pobres y en ellos la irrupción de Dios. Hay que traducir esta afirmación en la metodología teológica. Y revisar los manuales de teología fundamental en uso en América Latina.

La propuesta en sentido positivo podría formularse de esta manera. Utilizando la terminología de Cano, pero dando un paso más allá de él gracias sobre todo a la moderna conciencia histórica, puede afirmarse que la Iglesia y la teología están esencial y constitutivamente abiertas a la alteridad "ajena", no solo a los testimonios de la tradición "propia", a un "lugar teológico ajeno", en este caso el mundo de los pobres, que, gracias a un proceso de discernimiento es identificable como un posible "lugar teológico propio"-locus theologicus proprius-, incluso entre los llamados "principios propios y legítimos", en la terminología de M. Cano, en la medida en que se ha discernido en esa realidad

\footnotetext{
${ }^{53}$ Cf. DE AQUINO, F. "Sobre o método da teología da libertaçāo", pp. 403-407.

${ }^{54}$ DE AQUINO, F. “Teologia e ciencias sociais”. Horizonte 28 (2012), pp. 1344ss.

${ }^{55}$ El trabajo de J. Costadoat confirma esa insuficiencia. Se utilizan expresiones como "revelación", "Dios habla hoy", la "actual Palabra de Dios", etc. pero no queda aclarado el estatuto teológico de esa Palabra actual en la red de Palabras de Dios accesibles en las más diversas vías de transmisión. Cf. COSTADOAT, J. “El 'lugar teológico' en Jon Sobrino”. Theologica Xaveriana 181 (2016), pp. 23-49. La perspectiva fundamental de Sobrino queda clara, a mi juicio, en su sencilla formulación en la carta de 2007 a Kolvenbach, al enumerar "problemas de fondo importantes": "Los pobres como lugar de hacer teología. Es un problema de epistemología teológica, exigido o al menos sugerido por la Escritura. Personalmente, no dudo de que desde los pobres se ve mejor la realidad y se comprende mejor la revelación de Dios." Disponible en: $<$ http://2006.atrio.org/?p=565>. Acceso el 10 de julio 2017.
} 
histórica un fenómeno de revelación. ${ }^{56}$ De esta forma una determinada realidad histórica se convertiría en verdadera fuente insertada en una red epistemológica a partir de la cual la Iglesia vive y la teología piensa y argumenta.

\section{Consideraciones finales}

Se hace plena justicia al momento inductivo si lo que se escucha, con la ayuda de las más diversas mediaciones científicas y sapienciales es, no solo las voces humanas, sino en ellas y a través de ellas la Voz de Dios; la Palabra en las palabras. No se trata solo de leer e interpretar la praxis cristiana a la luz de la Palabra, entendiendo esta Palabra como los textos y mediaciones de la propia tradición. La propuesta de un uso diferenciado y análogo del concepto de revelación para la conceptualización de la Palabra de Dios que emerge en los acontecimientos históricos es una forma de precisar conceptualmente la novedad metodológica acaecida en estas décadas, particularmente a partir del proceso desencadenado por Gaudium et spes. ${ }^{57}$ Advierto que, legítimamente, se ha adoptado una idea diversa de lugar teológico en comparación a M. Cano, más allá incluso de la conciencia histórica que obliga a renovar y actualizar ese sistema de principios teológicos. Pero un punto, me parece, no ha colaborado en la precisión conceptual: la noción de lugar teológico se comprende en Cano al interior de un sistema de la fe y del creer, en una tradición eclesial con múltiples componentes, una red epistemológica de lugares teológicos. En ese sentido, la idea de lugar teológico no es un asunto individual, no existe un lugar teológico, sino una suma diferenciada y articulada de lugares -entre los que está la realidad histórica actual-gracias a los cuales nos llega la Palabra de Dios que no se identifica con ninguna de ellos, aunque tiene en la Escritura una vía de transmisión peculiar. Quizás el abandono o, mejor, simplemente la no consideración de ese sistema - renovado y actualizado- ha colaborado a la falta de precisión de la posible naturaleza revelatoria del presente en el marco de las otras vías de transmisión de la Palabra de Dios.

Ninguna de estas reflexiones cuestiona el método y la utilización de la categoría de lugar teológico referida por estos autores, sino solo en el punto esencial formulado que, por una parte, significaría una profundización ulterior en su misma forma de argumentar y, por otra, mostraría la finalidad

\footnotetext{
${ }^{56}$ Cf. CANO, M. De locis theologicis. Madrid: BAC, 2006, pp. 689-692.

${ }^{57}$ Cf. SCHICKENDANTZ, C. "Un cambio en la ratio fidei”, pp. 181-184.
} 
completamente teológica -sin quitarle consistencia al momento históricodel componente inductivo de la teología: a la escucha de la Palabra de Dios en la escucha de las palabras humanas. Esta perspectiva, además, podría ayudar a superar la "resistencia a una racionalidad inductiva e histórica", ${ }^{58}$ que ha emergido de distintas maneras en estas décadas en el posconcilio latinoamericano.

Las vacilaciones de varios de los mejores expertos del Concilio, como Y. Congar y K. Rahner, nos alertan acerca de la emergencia de una importante novedad en la historia del magisterio conciliar y de la metodología teológica, el inicio de "un nuevo capítulo de epistemología teológico-pastoral" deber ser justamente valorado y que, razonablemente, necesita desarrollo y maduración. En la categoría simbólica, bíblica y pastoral de signos de los tiempos, precisamente, se condensa este proceso de transformación manifestado en los dos desarrollos analizados en este artículo. De allí que no sorprenda el diagnóstico reciente de G. Ruggieri: no obstante "la fascinación que esta expresión despierta", una teología de los signos de los tiempos, que "se traduce en una hermenéutica de la historia bajo el signo de la esperanza mesiánica", "no puede considerarse hoy como adquirida". ${ }^{60}$

\section{Referencias bibliográficas}

BRIGHENTI, A. "Método ver-julgar-agir". In: DECIO PASSOS, J.; LOPES SANCHEZ, W. (Coord.). Dicionário do Concílio Vaticano II. São Paulo: Paulinas, 2015, pp. 608-615.

BRIGHENTI, A. "Documento de Aparecida: o texto original, o texto oficial e o Papa Francisco". Revista Pistis \& Práxis 3 (2016), pp. 673-713

CANO, M. De locis theologicis. Madrid: BAC, 2006.

CONGAR, Y. "Constitución sobre la Iglesia y el mundo (esquema XIII)". In: CONGAR, Y. Diario del Concilio. Cuarta sesión. Barcelona: Estela, 1966, pp. 57-64.

\footnotetext{
${ }^{58}$ BRIGHENTI, A. "Documento de Aparecida: o texto original, o texto oficial e o Papa Francisco”. Revista Pistis \& Práxis 3 (2016), p. 690.

${ }^{59}$ CONGAR, Y. Situación y tareas de la teología hoy. Salamanca: Ediciones Sígueme, 1970 , p. 89.

${ }^{60}$ RUGGIERI, G. Chiesa sinodale. Bari-Roma: Editori Laterza, 2017, pp. 219-220.
} 
CONGAR, Y. Situación y tareas de la teología hoy. Salamanca: Ediciones Sígueme, 1970.

CONGAR, Y. Mon Journal du Concile. Paris: Les Éditions du Cerf, 2002.

COSTADOAT, J. “El 'lugar teológico' en Jon Sobrino". Theologica Xaveriana 181 (2016), pp. 23-49.

DE AQUINO, F. "Sobre o método da teología da libertaçāo. Nos 20 anos do martírio de Ignacio Ellacuría". Perspectiva teológica 41 (2009), pp. 395-412.

DE AQUINO, F. "Sobre o conceito 'lugar teológico". Revista Eclesiástica Brasileira 278 (2010), pp. 451-453.

DE AQUINO, F. “Teologia e ciencias sociais”. Horizonte 28 (2012), pp. 13241349.

DE AQUINO, F. "El carácter social de la teología". Revista Latinoamericana de Teología 90 (2013), pp. 279-298.

DE AQUINO, F. Theologie als Einsicht in die Gottesherrschaft. Die Methode der Befreiungstheologie nach Ignacio Ellacuría. Regensburg: Verlag Friedrich Pustet, 2014.

ELLACURÍA, I. "Los pobres, lugar teológico en América Latina". In: ELLACURÍA, I. Escrito teológicos I. San Salvador: UCA Editores, 2000, pp. 139-161.

GEFFRÉ, C. "Théologie de l'incarnation et théologie des signes des temps chez le pére Chenu". In: Marie-Dominique Chenu. Moyen-Âge et modernité. Paris: Centre d'études du Saulchoir/Cerf, 1997, pp. 131-153.

GUTIÉRREZ, G. Teología de la liberación. Perspectivas. Lima: CEP, 1971.

KASPER, W. "El desafío permanente del Vaticano II. Hermenéutica de las aseveraciones conciliares". In: KASPER, W. Teología e Iglesia. Barcelona: Herder, 1989, pp. 410-413.

KASPER, W. Katholische Kirche. Wesen - Wirklichkeit - Sendung. Freiburg/ Basel/Wien: Herder Verlag, 2011.

MERINO, P. La categoría teológica Signos de los tiempos. Desde el Concilio Vaticano II al Pentecostés de Aparecida y Francisco. Bogotá: USTA, 2014.

MOELLER, C. "Pastorale Konstitution über die Kirche in der Welt von 
heute. Einleitung". In: Lexikon für Theologie und Kirche. Das Zweite Vatikanische Konzil III. Freiburg/Basel/Wien: Herder Verlag, 1968², pp. 242-279.

RAHNER, K. "Zur theologischen Problematik einer 'Pastoralkonstitution"”. In: RAHNER, K. Schriften zur Theologie. Vol 8. Einsiedeln: Benziger Verlag, 1967, pp. 613-636, 613. (Texto incluido en las Obras completas en: RAHNER, K. Sämtliche Werke. Das Zweite Vatikanum. Bd. 21/2. Freiburg/Basel/Wien: Herder Verlag, 2013, pp. 904-922).

RAHNER, K. "Über die Frage einer formalen Existentialethik". In: RAHNER, K. Sämtliche Werke. Kirche in den Herausforderung der Zeit. Bd. 10. Freiburg/Basel/Wien: Herder Verlag, 2003, pp. 302-316.

RAHNER K. "Die Logik der existentiellen Erkenntnis bei Ignatius von Loyola". In: RAHNER, K. Sämtliche Werke. Kirche in den Herausforderung der Zeit. Bd. 10. Freiburg/Basel/Wien: Herder Verlag, 2003, pp. 368-420.

RAHNER, K. "Animadversiones de Schemate 'De Ecclesia in mundo huius temporis”. In: RAHNER, K Sämtliche Werke. Ergänzungen. Bd. 32/1. Freiburg/Basel/Wien: Herder Verlag, 2016, pp. 289-317.

ROUTHIER, G. "Finalizar la obra comenzada: la experiencia del cuarto período, una experiencia que ponía a prueba". In: ALBERIGO, G. (Dir.). Historia del Concilio Vaticano II. Volumen V. Un Concilio de transición. El cuarto período y la conclusión del Concilio. Salamanca: Sígueme, 2008, pp. 59-177.

ROUTHIER, G. “'Les signes du temps'. Fortune et infortune d'une expression du Concile Vatican II”. Transversalités 118 (2011), pp. 79-102.

RUGGIERI, G. Chiesa sinodale. Bari-Roma: Editori Laterza, 2017.

SANDER, H-J. "Theologischer Kommentar zur Pastoralkonstitution über die Kirche in der Welt von heute Gaudium et spes". In : HÜNERMANN, P.; HILBERATH, B.-J. (Eds.). Herders Theologischer Kommentar zum Zweiten Vatikanischen Konzil. Band 4. Freiburg/Basel/Wien: Herder Verlag, 2005, pp. 581-886.

SCHICKENDANTZ, C. "Autoridad teológica de los acontecimientos históricos: perplejidades sobre un lugar teológico". Teología 115 (2014), pp. 157-183.

SCHICKENDANTZ, C. “¿Una transformación metodológica inadvertida? 
La novedad introducida por Gaudium et spes en los escritos de Joseph Ratzinger”. Teología y Vida 57 (2016), pp. 9-37.

SCHICKENDANTZ, C. "Un cambio en la ratio fidei. Asociación (aparentemente ilícita) entre principios teológicos y datos empíricos". Teología y Vida 57 (2016), pp. 157-184.

SOBRINO, J. "Carta de Jon Sobrino al P. general de los jesuitas". Disponible en: $<$ http://2006.atrio.org/?p=565>. Acceso el 10 de julio 2017.

THEOBALD, C. Le concile Vatican II. Quel avenir? Cerf: Paris, 2015.

TURBANTI, G. Un Concilio per il mondo moderno. La redazione della costituzione pastorale 'Gaudium et spes' del Vaticano II. Bologna: Il Mulino, 2000.

\section{Carlos Schickendantz}

Doctor en Teología por la Eberhard-Karls-Universität Tübingen (Alemania) Investigador del Centro Teológico Manuel Larraín de la Universidad Alberto Hurtado Santiago - Chile E-mail: cschickend@uahurtado.cl

Recebido em: 27/11/17

Aprovado em: 30/11/17 